\title{
Follicle Structure Influences the Availability of Oxygen to the Oocyte in Antral Follicles
}

\author{
A. R. Clark ${ }^{1}$ and Y. M. Stokes ${ }^{2}$ \\ ${ }^{1}$ Auckland Bioengineering Institute, The University of Auckland, Auckland 1142, New Zealand \\ ${ }^{2}$ School of Mathematical Sciences, The University of Adelaide, Adelaide, SA 5000, Australia \\ Correspondence should be addressed to A. R. Clark, alys.clark@auckland.ac.nz
}

Received 2 March 2011; Revised 2 August 2011; Accepted 31 August 2011

Academic Editor: Thierry Busso

Copyright (C) 2011 A. R. Clark and Y. M. Stokes. This is an open access article distributed under the Creative Commons Attribution License, which permits unrestricted use, distribution, and reproduction in any medium, provided the original work is properly cited.

\begin{abstract}
The ability of an oocyte to successfully mature is highly dependent on intrafollicular conditions, including the size and structure of the follicle. Here we present a mathematical model of oxygen transport in the antral follicle. We relate mean oxygen concentration in follicular fluid of bovine follicles to the concentration in the immediate vicinity of the cumulus-oocyte complex (COC). The model predicts that the oxygen levels within the antral follicle are dependent on the size and structure of the follicle and that the mean level of dissolved oxygen in follicular fluid does not necessarily correspond to that reaching the COC.
\end{abstract}

\section{Introduction}

A mammalian oocyte develops within a follicle in the ovary. The presence and growth of the follicle is likely to affect nutrient levels reaching the oocyte, and intrafollicular conditions may have an influence on the developmental competence of oocytes (the ability to mature, be fertilized, and develop into an embryo [1]) that does not become evident until some time after fertilisation [2]. The success of assisted reproduction technologies relies on developmentally competent oocytes being selected for treatment. The level of follicular vascularity, which directly affects the supply of nutrient to the follicle, has been linked to in vitro fertilisation (IVF) outcomes [3], and the nutrient composition of intrafollicular fluid has been studied as a prognostic parameter for selecting oocytes for IVF [4].

While traditional IVF uses oocytes matured in vivo, it can be desirable, or even necessary, to use immature oocytes which must first be matured in the laboratory, a process known as in vitro maturation (IVM). IVM is not widespread in humans, although it has potential to become a viable alternative to traditional IVF in cases where the mother is susceptible to ovarian hyperstimulation syndrome (OHSS) or polycystic ovary syndrome (PCOS) [5-8]. IVM is however used routinely in ruminants such as cattle where management of reproduction is an important industry concern $[1,9]$. The development of IVM systems that optimise the successful development of the embryo has long been identified as essential in both commercial and research settings [10]. However, the success of IVM suffers from differences between the nutrient composition in culture media compared with in vivo conditions $[11,12]$; hence, an understanding of intrafollicular conditions is critical for successful oocyte selection and maturation regardless of species.

The avascular part of the follicle structure is shown schematically in the antral stage of development in Figure 1. This structure consists of the follicle wall (made up of mural granulosa cells), surrounding a region comprised of follicular fluid (the antrum). The oocyte and its surrounding layers of cumulus cells, known collectively as the cumulus-oocyte complex (COC), are eccentrically placed within the follicle. In some follicles (particularly smaller follicles), the COC sits partially within the follicle wall; however, in many follicles it rests within the antrum, either next to the follicle wall or attached to it by a "stem" of granulosa cells. Surrounding the avascular part of the follicle is the basal lamina and the theca externa and theca interna (not shown in Figure 1). The vascular supply to the follicle, and so the supply of nutrients 


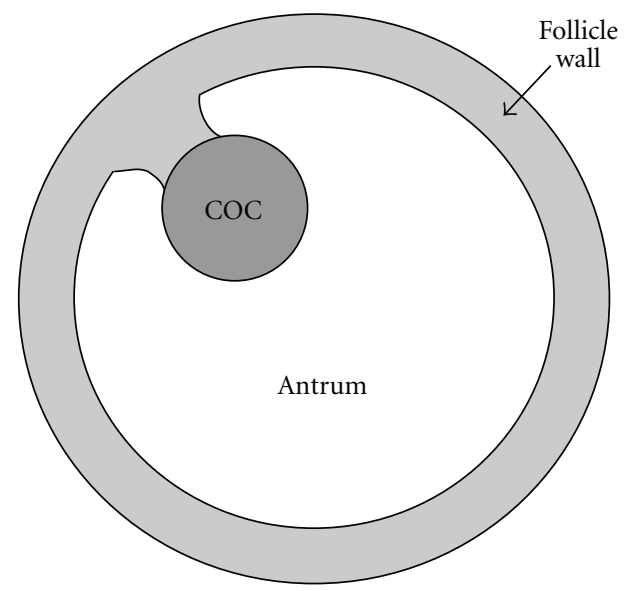

FIgURE 1: The antral follicle with the follicle wall, the antrum, and the COC labelled. In some follicles (particularly smaller follicles), the COC sits partially within the follicle wall; however, in many follicles it rests within the antrum, either next to the follicle wall or attached to it by a "stem" of granulosa cells as shown here.

to the oocyte, lies in theca layers around the perimeter of the follicle.

The composition of follicular fluid varies between follicles and depends on their size and structure [4, 13]. Each antral follicle has a unique follicular fluid composition, and, despite several experimental studies, it is still not clear what constitutes a follicular environment that allows oocytes to develop successfully $[2,4]$. Without a quantitive description of in vivo conditions the development of in vitro systems must rely to some extent on a "trial and error" approach. Mathematical modelling of nutrient transport in the follicle provides understanding of how the follicular environment affects the levels of nutrient seen by the oocyte. Previous mathematical models of nutrient transport in the antral follicle focus on investigation of oxygen $\left(\mathrm{O}_{2}\right)$ transport [14, 15]. These studies treat the follicle wall as a homogeneous mass of cells and do not explicitly consider the COC, which is assumed to lie within, and behave in the same manner as, the follicle wall. We explicitly include the COC in our model under the hypothesis that the oocyte protrusion into the follicle may affect its nutrient environment. To our knowledge, this explicit inclusion of the COC within the follicle has not been considered in modelling studies.

Several experimental studies indicate that perifollicular vascularity is associated with oocyte developmental competence $[2,16]$. This has in turn been associated with the dissolved $\mathrm{O}_{2}$ content of follicular fluid [16], although this association has been disputed [17]. While $\mathrm{O}_{2}$ is clearly essential for successful oocyte maturation, very high $\mathrm{O}_{2}$ levels can result in an increased presence of, for example, reactive oxygen species (ROS), which can be damaging to the oocyte [18]. Studies examining the effect of $\mathrm{O}_{2}$ concentration during in vitro maturation of oocytes across several species have not yielded a consensus on the optimal $\mathrm{O}_{2}$ concentration for oocyte maturation, due to conflicting results [19-24]. Here we present a mathematical model which relates perifollicular
$\mathrm{O}_{2}$ concentration to follicular fluid $\mathrm{O}_{2}$ concentration and the $\mathrm{O}_{2}$ concentration reaching the COC in antral follicles.

Thus, this model is the first of its kind to explicitly include a COC, which allows prediction of the nutrient environment near the oocyte itself, as well as whole follicle measures. The model predicts that the $\mathrm{O}_{2}$ levels within the antral follicle are dependent on the size and structure of the follicle and that the average level of dissolved $\mathrm{O}_{2}$ in follicular fluid does not necessarily correspond to that reaching the COC.

\section{Mathematical Model}

2.1. Model Geometry. The model proposed here considers the follicle wall, the antrum, and the COC as three separate regions. The antral follicle is approximated as an axially symmetric structure, with rotational symmetry about the line that passes through both the centre of the follicle and the centre of the COC. The model geometry is shown in Figure 2 with the COC in two different positions within the follicle. The origin is chosen as the centre of the COC (labelled $O$ in Figure 2) and is distance $d$ from the centre of the follicle. An appropriate coordinate system is $(\rho, \theta)$, where $\rho \geq 0$ is radial distance from the origin and $\theta$ is the angle shown in Figure 2(a). The axially symmetric geometry is described by considering $0 \leq \theta \leq \pi$. As the origin is at the centre of the COC, the boundary at the edge of the COC is described by $\rho=r_{C}$, where $r_{C}$ is the constant radius of the COC. The boundaries of the antrum, $\rho_{A}(\theta)$, and the follicle, $\rho_{F}(\theta)$, are

$$
\begin{array}{ll}
\rho_{A}(\theta)=\sqrt{r_{A}^{2}-d^{2} \sin (\theta)}-d \cos (\theta), & \theta^{*} \leq \theta \leq \pi, \\
\rho_{F}(\theta)=\sqrt{r_{F}^{2}-d^{2} \sin (\theta)}-d \cos (\theta), & 0 \leq \theta \leq \pi,
\end{array}
$$

where $r_{A}$ is the radius of the antrum and $r_{F}$ the radius of the follicle as measured from the center of the follicle. When the COC is partially embedded in the follicle wall, $\theta^{*}$ is the value of $\theta$ at which the COC and the antrum intersect and

$$
\theta^{*}=\arccos \left(\frac{r_{A}^{2}-r_{C}^{2}-d^{2}}{2 d r_{C}}\right) .
$$

If the COC is completely within the antrum, then $\theta^{*}=0$ in (1).

The rate of follicle growth is assumed to be slow compared with the rate of $\mathrm{O}_{2}$ transport within the follicle. Thus, a steady-state model at each stage of follicle development is appropriate. The antral fluid is formed from transudate from blood plasma and also secretions from granulosa cells, cumulus cells, and the oocyte [25]; this may result in fluid motion and hence mixing. It is assumed that any fluid motion is negligible and so the dominant mechanism of $\mathrm{O}_{2}$ transport throughout the follicle is by diffusion. In the antrum itself, it is assumed that $\mathrm{O}_{2}$ consumption is negligible; therefore, $\mathrm{O}_{2}$ concentration in the antrum, $c_{A}$, satisfies Laplace's equation

$$
\frac{\partial}{\partial \rho}\left(\rho^{2} \frac{\partial c_{A}}{\partial \rho}\right)+\frac{1}{\sin \theta} \frac{\partial}{\partial \theta}\left(\sin \theta \frac{\partial c_{A}}{\partial \theta}\right)=0
$$




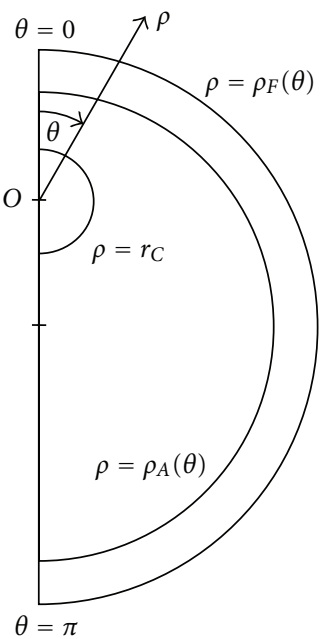

(a)

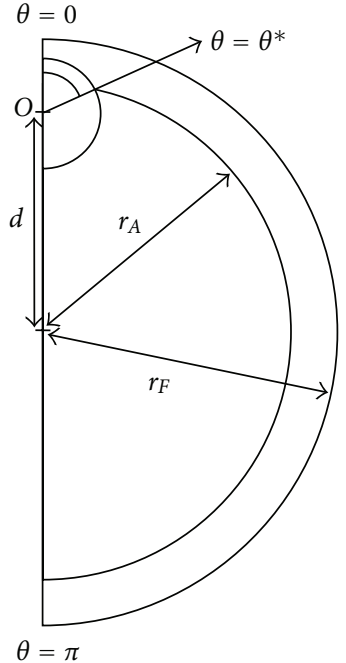

(b)
FIGURE 2: The model geometry used to represent the antral follicle. This geometry is described using polar coordinates $(\rho, \theta)$ with axial symmetry. The origin of the geometry is taken to be the centre of the COC, and thus the origin varies with respect to the antrum and the follicle wall. The geometry is shown for (a) the COC entirely within the antrum and (b) the COC partially enclosed within the antrum and partially within the follicle wall, intersecting the inner boundary of this layer at $\theta=\theta^{*}$.

In the follicle wall we assume that the cumulus cells can be treated as a homogenous layer of intra- and extracellular matter, as in previous models of $\mathrm{O}_{2}$ transport in the antral follicle $[14,15]$. Therefore, the $\mathrm{O}_{2}$ concentration in the follicle wall, $c_{G}$, satisfies

$$
\frac{D_{G}}{\rho^{2}} \frac{\partial}{\partial \rho}\left(\rho^{2} \frac{\partial c_{G}}{\partial \rho}\right)+\frac{D_{G}}{\rho^{2} \sin \theta} \frac{\partial}{\partial \theta}\left(\sin \theta \frac{\partial c_{G}}{\partial \theta}\right)=\left(1-\alpha_{G}\right) q_{G},
$$

where $D_{G}$ is the diffusion coefficient of $\mathrm{O}_{2}$ in the follicle wall, $\alpha_{G}$ is the volume fraction of extracellular material in the follicle wall (the ratio of extracellular to total volume), and $q_{G}$ is the rate of $\mathrm{O}_{2}$ uptake by granulosa cells (amount per unit volume of granulosa cell mass per unit time). Experimental determination of oxygen consumption by ovine granulosa cells and murine embryos has indicated little dependence on $\mathrm{O}_{2}$ concentration, except at very low concentrations $[26,27]$. The function $q_{G}$ is therefore assumed to be independent of $\mathrm{O}_{2}$ concentration as in previous studies of $\mathrm{O}_{2}$ transport in granulosa cells, embryos, and follicles [14, 15, 26, 27].

Consumption of $\mathrm{O}_{2}$ by the $\mathrm{COC}$ is incorporated into this model via a flux condition at the COC boundary

$$
\begin{array}{ll}
D_{G} \frac{\partial c_{G}}{\partial \rho}\left(r_{C}, \theta\right)=q_{\text {COC }}, & 0 \leq \theta \leq \theta^{*}, \\
D_{A} \frac{\partial c_{A}}{\partial \rho}\left(r_{C}, \theta\right)=q_{\text {COC }}, & \theta^{*} \leq \theta \leq \pi,
\end{array}
$$

where $D_{A}$ is the diffusion coefficient of $\mathrm{O}_{2}$ in the antrum and $q_{\text {COC }}$ is the rate of $\mathrm{O}_{2}$ uptake by the COC (amount per unit COC surface area per unit time). As with the rate of $\mathrm{O}_{2}$ uptake by granulosa cells, the rate of $\mathrm{O}_{2}$ uptake by the COC is assumed constant.

At the boundary between the follicle wall and the antrum continuity of flux and concentration hold. Symmetry conditions apply at $\theta=0$ and $\theta=\pi$ in both the follicle wall and the antrum.

The flux of $\mathrm{O}_{2}$ into the follicle at the boundary $\rho_{F}(\theta)$, the edge of the follicle, is represented by

$$
D_{G} \frac{\partial c_{G}}{\partial n_{F}}\left(\rho_{F}(\theta), \theta\right)=h_{p}\left(c_{P}-c_{G}\left(\rho_{F}(\theta), \theta\right)\right),
$$

where $c_{P}$ is the $\mathrm{O}_{2}$ concentration in the blood vessels surrounding the follicle and $\partial c_{G} / \partial n_{F}$ is the concentration gradient in the direction of the outward unit normal vector to the follicle surface. The parameter $h_{p}$ is the transfer coefficient for this problem and quantifies the ease of $\mathrm{O}_{2}$ transport from the vascular network of the ovary into the follicle.

Model parameters for the bovine antral follicle and a parameter sensitivity analysis are given in Table 1 . The diffusion coefficients of $\mathrm{O}_{2}$ in the antrum and the follicle wall are assumed to be that of $\mathrm{O}_{2}$ in physiological saline [28]. An average bovine preovulatory follicle diameter is $15-18 \mathrm{~mm}$ [29]. However, bovine ovulatory follicle radius is highly variable, depending on the number of follicles ovulated, breed, age, and any hormones administered. A study using ultrasonography classified follicles by animal age, the number of follicles ovulated, and the year (20042006) and showed bovine preovulatory follicle diameters ranging from 8 to $30 \mathrm{~mm}$ (radii of $4-15 \mathrm{~mm}$ ), with a mean in each group considered ranging from 13.9 to $17.1 \mathrm{~mm}$ (radius $6.95-8.55 \mathrm{~mm}$ ) [29]. Therefore, a range of follicle radius values, $r_{F}$, up to $15 \mathrm{~mm}$ were considered to allow consideration of antral follicles through development to ovulation. There is no apparent relationship between the radius of a follicle and the thickness of its follicle wall in bovine antral follicles [30, 31], and there appears to be considerable variation in granulosa cell numbers between follicles [15]. However, a relationship between granulosa cell number $\left(n_{G}\right)$ and follicle radius has been determined in humans by Redding et al. [15] as

$$
n_{G}=\frac{a}{1+b e^{2 c r_{F}}}
$$

where $a, b$, and $c$ are constants. The antrum radius, $r_{A}$, is then calculated using

$$
\text { Follicle wall volume }=\frac{n_{G} v_{G}}{1-\alpha_{G}}=\frac{4 \pi r_{F}^{3}}{3}-\frac{4 \pi r_{A}^{3}}{3},
$$

where $v_{G}$ is the volume of a granulosa cell. The volume fraction of extracellular material in the follicle wall of a bovine follicle, $\alpha_{G}$, is not well determined. A value of $\alpha_{G}=$ 0.3 is thought to be typical of volume fractions in the follicle wall of mammalian follicles $[14,15]$ and is used in previous studies of $\mathrm{O}_{2}$ transport in the antral follicle. However, as discussed in those studies, accurate experimental determination of this volume fraction would benefit models 
TABLE 1: Nominal model parameters and sensitivity analysis. The sensitivity analysis is carried out by considering the nominal parameter values as the baseline (with the COC centrally located within the follicle) and calculating the change in the mean $\mathrm{O}_{2}$ concentration at the COC boundary $\left(r_{C}\right)$ for a $10 \%$ increase or decrease in each parameter from the baseline.

\begin{tabular}{|c|c|c|c|c|}
\hline Parameter & Value & Reference & $+10 \%$ & $-10 \%$ \\
\hline$\alpha_{G}$ & 0.3 (no units) & {$[14,15]$} & $-1.5 \%$ & $+1.4 \%$ \\
\hline$C_{P}$ & $0.128\left(\mathrm{~mol} \mathrm{~m}^{-3}\right)$ & {$[14]$} & $+41 \%$ & $-41 \%$ \\
\hline$D_{A}$ & $2.5 \times 10^{-9}\left(\mathrm{~m}^{2} \mathrm{~s}^{-1}\right)$ & {$[28]$} & $+25 \%$ & $-30 \%$ \\
\hline$D_{G}$ & $2.5 \times 10^{-9}\left(\mathrm{~m}^{2} \mathrm{~s}^{-1}\right)$ & {$[28]$} & $+3.1 \%$ & $-3.7 \%$ \\
\hline$h_{P}$ & $0.1\left(\mathrm{~m} \mathrm{~s}^{-1}\right)$ & Variable (see text) & See discussion & See discussion \\
\hline$q_{G}$ & $0.0363\left(\mathrm{~mol} \mathrm{~m}^{-3} \mathrm{~s}^{-1}\right)$ & {$[14]$} & $-3.1 \%$ & $+3.1 \%$ \\
\hline$q_{\mathrm{COC}}$ & $1.62 \times 10^{-6}\left(\mathrm{~mol} \mathrm{~m}^{-2} \mathrm{~s}^{-1}\right)$ & $\begin{array}{l}\text { From [44], units converted } \\
\text { using } r_{C}\end{array}$ & $-28 \%$ & $+28 \%$ \\
\hline$r_{F}$ & $1 \times 10^{-3}(\mathrm{~m})$ & See text & $+1.9 \%$ & $-4.5 \%$ \\
\hline$r_{C}$ & $160 \times 10^{-6}(\mathrm{~m})$ & {$[45]$} & $+30 \%$ & $-37 \%$ \\
\hline$v_{G}$ & $1.14 \times 10^{-15}\left(\mathrm{~m}^{3}\right)$ & {$[15]$} & $-6.9 \%$ & $+6.2 \%$ \\
\hline$a$ & $43.1 \times 10^{6}$ & {$[15]$} & $-6.9 \%$ & $+6.2 \%$ \\
\hline$b$ & 281.6 & {$[15]$} & $+5.6 \%$ & $-7.6 \%$ \\
\hline$c$ & -387.3 & {$[15]$} & $-5.4 \%$ & $+4.6 \%$ \\
\hline
\end{tabular}

of this type. The magnitude of the parameter $h_{p}$ is unknown and so a range of values for this parameter was considered; model solutions were insensitive to $h_{p}$ for $h_{P}>0.01 \mathrm{~m} / \mathrm{s}$.

In the special case that the COC lies at the centre of the follicle the model described by (3)-(6) is analytically solvable. Although this is an unlikely physical scenario, especially in large follicles, it provides validation of numerical solution procedures. Also, as will be discussed in Section 3 of this study, it provides a "worst case" solution where predicted $\mathrm{O}_{2}$ concentrations reaching the COC are lowest. The model of Redding et al. [14, 15], which incorporates the COC mass into the follicle wall is also considered here, holding total cell mass (COC plus granulosa cells) constant between models. This model is also analytically solvable and provides a "best case" scenario where predicted $\mathrm{O}_{2}$ concentrations reaching the COC are highest. When numerical solutions were necessary, they were obtained using the finite element solver COMSOL Multiphysics (Version 3.3, COMSOL AB, 2006). The solutions are shown here in two cases: (1) with the COC resting on the inner surface of the follicle wall, and (2) with the COC within the antrum one COC radius $\left(r_{C}\right)$ away from the follicle wall.

\section{Results}

When the COC cell mass is incorporated into the follicle wall, the predicted $\mathrm{O}_{2}$ concentration in the antrum is constant and equal to that at the inner boundary of the follicle wall, which is little less than the perifollicular concentration $c_{P}$. However, when the COC is explicitly included in modeling, there is a significant decrease in $\mathrm{O}_{2}$ concentration in the vicinity of it. Figure 3 shows $\mathrm{O}_{2}$ concentrations (normalized by $c_{P}$ ) in a follicle of $1 \mathrm{~mm}$ radius for the COC in two different positions in the antrum.

It is straightforward for experimentalists to measure the mean dissolved $\mathrm{O}_{2}$ concentration in follicular fluid, whereas it is very difficult to measure the $\mathrm{O}_{2}$ concentration in the vicinity of the COC, particularly in vivo. This mean $\mathrm{O}_{2}$ concentration, as predicted by our model, is plotted versus follicle radius in Figure 4 for (A) the COC incorporated into the follicle wall, (B) the COC resting on the inner boundary of the follicle wall, $(\mathrm{C})$ the $\mathrm{COC}$ a distance of one radius $\left(r_{C}\right)$ away from the follicle wall, and (D) the COC at the centre of the follicle. Case (A) is the model considered by Redding et al. [14, 15] for human follicles, and our results correspond to that model when the human parameter values from those studies are used. Cases (A) and (D), respectively, provide a maximum and a minimum for predictions of mean follicular fluid $\mathrm{O}_{2}$ concentration and solutions do not differ substantially in this case. A typical ovulatory follicle radius range [29] is shown, and this corresponds to a local minimum in $\mathrm{O}_{2}$ concentration.

However, model predictions of the mean $\mathrm{O}_{2}$ concentration at the COC surface in each case differ substantially from predictions of mean $\mathrm{O}_{2}$ concentration in follicular fluid (Figure 5(a)). It is clear that the closer the COC to the centre of the antrum, the lower the $\mathrm{O}_{2}$ concentration at its surface. Figure 5(b) shows the ratio of the mean $\mathrm{O}_{2}$ concentration in follicular fluid to the mean $\mathrm{O}_{2}$ concentration at the COC surface in the cases where the COC is explicitly included in modelling (cases $\mathrm{B}, \mathrm{C}, \mathrm{D}$ ). When the COC rests on the follicle wall (case $\mathrm{B}$ ), the level of $\mathrm{O}_{2}$ reaching the COC is just $60 \%$ of the follicular fluid average, and this ratio decreases as the COC gets closer to the centre of the antrum.

The model is highly sensitive to the diffusion coefficients $D_{A}$ and $D_{G}$. There is some discussion in the literature about the appropriate diffusion coefficient for oxygen in tissues (see [32] for a thorough discussion of the literature regarding this matter). If it were the case that either diffusion coefficient was lower than that in physiological saline, this would reduce $\mathrm{O}_{2}$ concentrations throughout the antrum and at the COC surface but would not change the qualitative nature of results. 


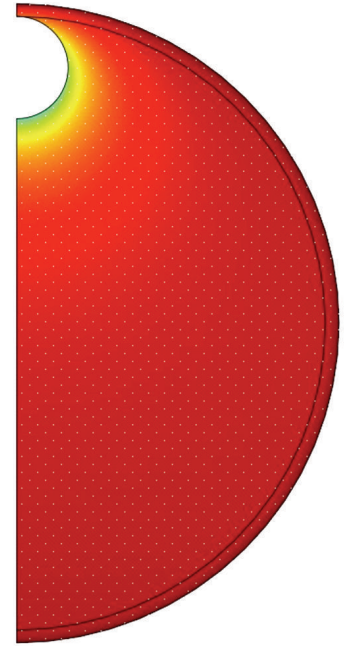

(a)

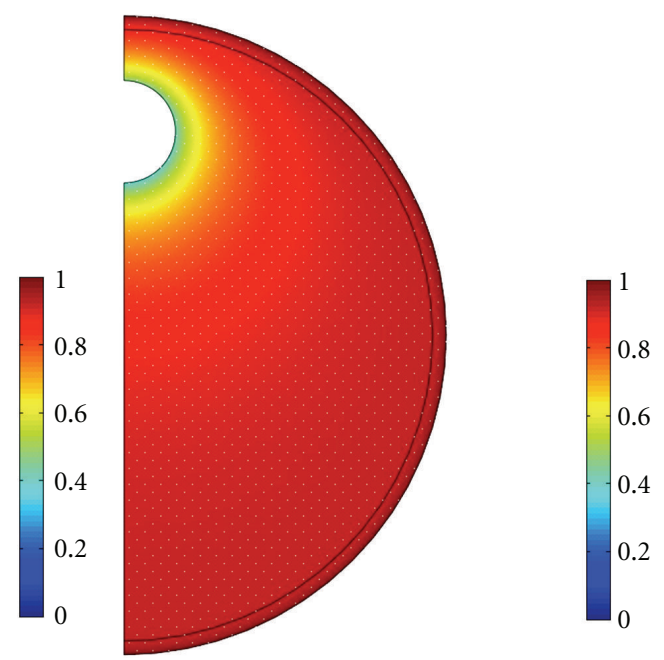

(b)

FIGURE 3: The $\mathrm{O}_{2}$ concentrations (normalized by $c_{P}$ ) in a follicle of $1 \mathrm{~mm}$ radius when (a) the COC rests on the inner boundary of the follicle wall and (b) the COC is a distance of one radius $\left(r_{C}\right)$ away from the follicle wall. Explicit inclusion of the COC in the model shows a decrease in $\mathrm{O}_{2}$ concentration within the antrum in the vicinity of the COC.

Similarly changes to $q_{\mathrm{COC}}$ and $r_{C}$, properties of the COC to which the model is sensitive, do not change the qualitative nature of results.

\section{Discussion}

Here we have described the construction of a mathematical model to describe $\mathrm{O}_{2}$ transport in the antral follicle which explicitly includes a COC which may protrude into, or lie entirely within, the antrum. This model enables linking of follicular $\mathrm{O}_{2}$ concentration, a measurable quantity which has been proposed as a prognostic parameter in assisted reproduction technologies, and the $\mathrm{O}_{2}$ environment of the oocyte. Model results show that the structure of the follicle is important in determining $\mathrm{O}_{2}$ availability to the oocyte, and so this structure is also likely to affect developmental competence, a factor which may be important when selecting oocytes for assisted reproduction.

Model predictions of mean $\mathrm{O}_{2}$ concentration in follicular fluid show the same form as those obtained using the model of $\mathrm{O}_{2}$ transport in the antral follicle described by Redding et al. $[14,15]$, which did not explicitly include a COC. Results from these studies, and the work described in this paper, give understanding of the level of dissolved $\mathrm{O}_{2}$ in an antral follicle at different stages of development. At the start of the antral stage predicted mean $\mathrm{O}_{2}$ concentration rises rapidly with follicle radius to a local maximum at a radius of $2-3 \mathrm{~mm}$ (Figure 4). At this stage follicle growth is predominantly due to antrum formation, rather than granulosa cell proliferation. An increasing follicular surface area and decreasing follicle wall thickness (as a fraction of follicle radius) allow more $\mathrm{O}_{2}$ to enter the follicle resulting in the observed increase in $\mathrm{O}_{2}$ concentration with follicle radius. Later in follicle growth, granulosa cell proliferation

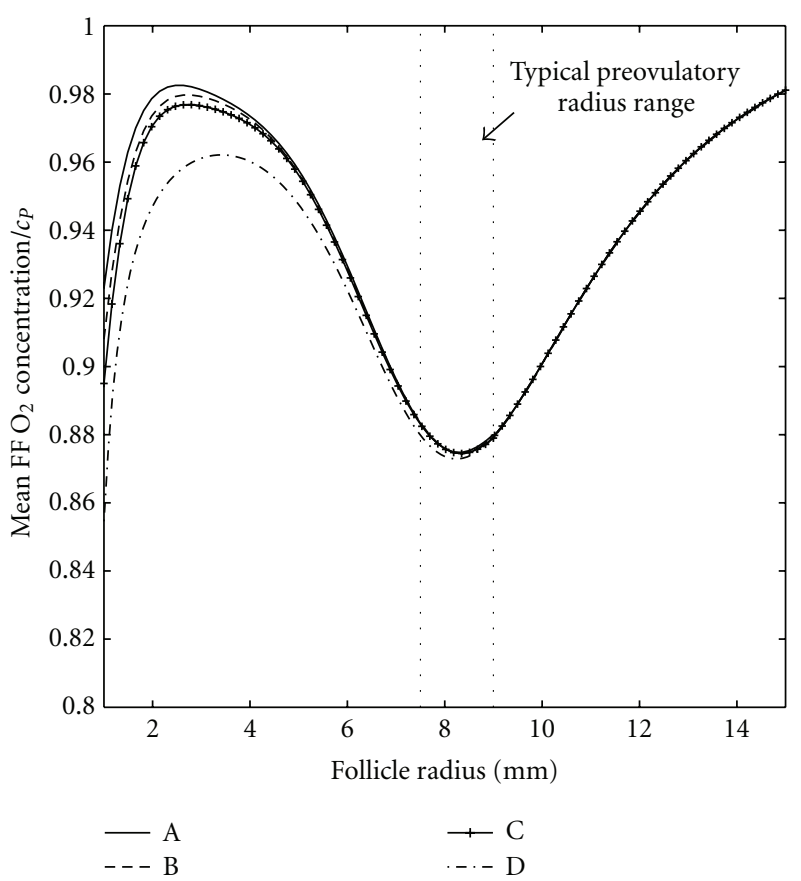

FIGURE 4: Mean follicular fluid (FF) $\mathrm{O}_{2}$ concentration versus follicle radius for (A) the COC incorporated into the follicle wall, (B) the COC resting on the inner boundary of the follicle wall, $(C)$ the COC a distance of one radius $\left(r_{C}\right)$ away from the follicle wall, and (D) the $\mathrm{COC}$ at the centre of the follicle wall.

increases the thickness of the follicle wall resulting in a decrease in $\mathrm{O}_{2}$ concentration within the antrum.

There is a local minimum in $\mathrm{O}_{2}$ concentration predicted by the model at around $8 \mathrm{~mm}$ radius $(16 \mathrm{~mm}$ diameter) which falls within the range of typical diameters for bovine 


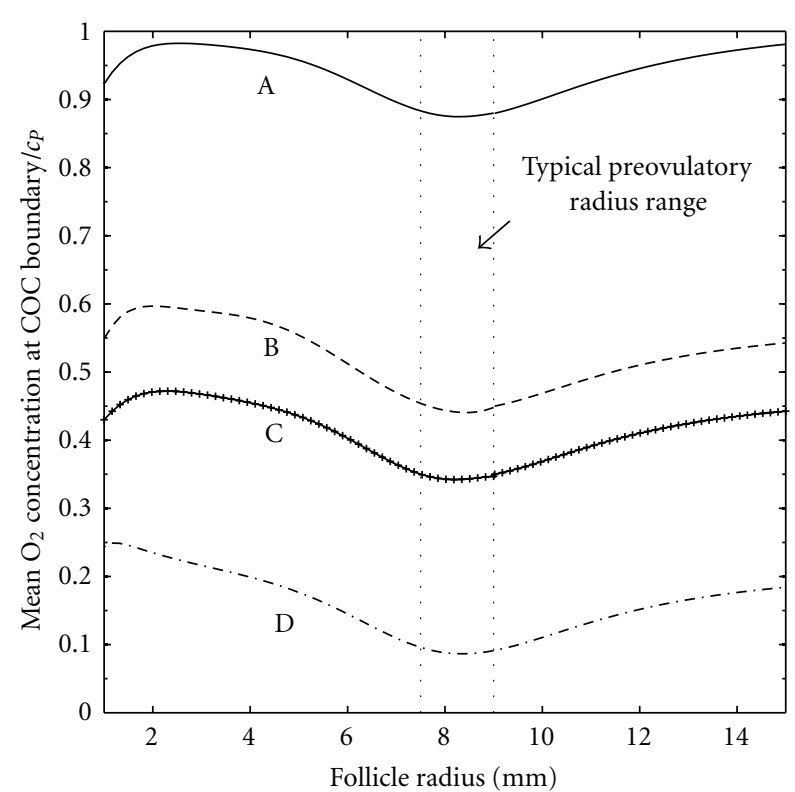

(a)

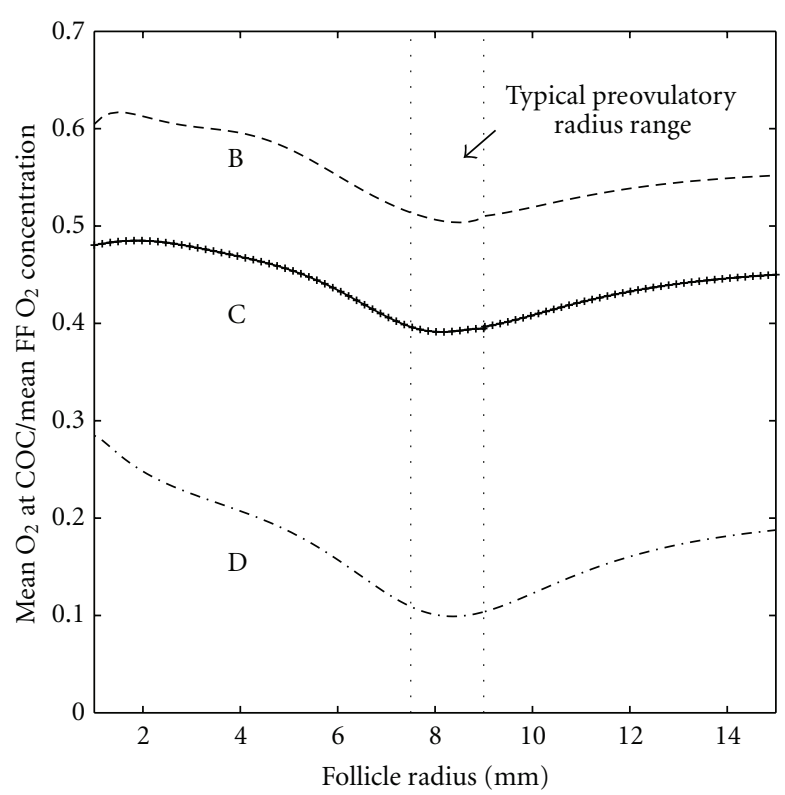

(b)

Figure 5: (a) Mean $\mathrm{O}_{2}$ concentration at the surface of the COC versus follicle radius for (A) the COC incorporated into the follicle wall, (B) the COC resting on the inner boundary of the follicle wall, $(\mathrm{C})$ the COC a distance of one radius $\left(r_{C}\right)$ away from the follicle wall, and (D) the $\mathrm{COC}$ at the centre of the follicle wall. (b) The ratio of mean $\mathrm{O}_{2}$ concentration at the surface of the COC to mean follicular fluid (FF) $\mathrm{O}_{2}$ concentration plotted against follicle radius for the cases when the COC is explicitly included in modelling (cases B-D).

ovulatory follicles. Beyond that radius the $\mathrm{O}_{2}$ concentration within the follicle steadily rises toward a global maximum which, in the case of mean follicular fluid $\mathrm{O}_{2}$ concentration, is close to plasma $\mathrm{O}_{2}$ concentration. This implies that larger than average preovulatory follicles, provided that they are sufficiently vascularised, will see a larger than average $\mathrm{O}_{2}$ concentration. Whether this is beneficial or detrimental to their subsequent development when fertilised is likely to depend on the associated level of ROS, which is known to increase at high $\mathrm{O}_{2}$ concentrations. In bovine IVM it has been shown that the developmental potential of an oocyte increases with follicle (and oocyte) diameter in follicles up to $15 \mathrm{~mm}$ in diameter [33]. In studies using hormonal treatment to induce ovulation before artificial insemination, the pregnancy rate increased with follicle diameter to, approximately, $12-15 \mathrm{~mm}$ in diameter and then decreased as follicle size increased further $[34,35]$. However, changes in pregnancy rate with follicle diameter were not detected in spontaneously ovulating cows [34].

An important difference between our model and previous models is the explicit inclusion of the COC. This allows the position of the COC within the follicle to be altered to determine the effects of follicle geometry on the $\mathrm{O}_{2}$ environment within the follicle. Average $\mathrm{O}_{2}$ concentrations in follicular fluid are higher the closer the COC sits to the follicle wall, and neglecting the COC from models will necessarily overestimate the $\mathrm{O}_{2}$ seen by the COC, unless the COC is completely incorporated into the follicle wall. Our model suggests that the position of the COC within the follicle plays a significant role in determining the $\mathrm{O}_{2}$ concentration seen by the oocyte and that follicle structure should be taken into account, along with average dissolved follicular fluid $\mathrm{O}_{2}$ concentration, in order to understand the effect of $\mathrm{O}_{2}$ concentration on the developmental competence of the oocyte. The influence of follicle geometry on the $\mathrm{O}_{2}$ availability to the COC may give some indication as to why the dissolved $\mathrm{O}_{2}$ content of follicular fluid has not been conclusively linked to developmental competence of oocytes $[16,17]$.

In terms of cattle breeding or even human IVM systems that aim to replicate the in-vivo environment, the finding that average follicular fluid oxygen concentration is likely to be considerably higher than that reaching the COC should be taken into account when considering optimal incubator settings. The geometry of an in vitro environment may also influence the availability of $\mathrm{O}_{2}$ to the COC-for example, the volume of fluid in which the COC is matured may alter $\mathrm{O}_{2}$ availability-and this may need to be accounted for when determining incubator settings for IVM.

Figure 3 shows that the drop in oxygen concentration across the mural granulosa follicle wall is small while there is a significant decrease in follicular oxygen concentration in the vicinity of the COC. This implies that the granulosa cells do not play a large role in determining follicular fluid oxygen concentrations so sparing oxygen for use by the maturing oocyte. The parameter describing oxygen uptake by mural granulosa is a factor of ten lower than that describing oxygen consumption by cumulus cells (the cells directly surrounding the oocyte) given by Clark et al. [32]. There is in vitro evidence from murine $[36,37]$ and bovine [38] studies that, in the absence of follicle stimulating hormone (FSH), the metabolism of cumulus and granulosa cells differs 
significantly. This suggests differing roles for the granulosa and cumulus cells in supporting the developing oocyte. Models show that both the cumulus cells [32] and the granulosa cells (modelled here) appear to spare oxygen, which is necessary for ATP production within the oocyte. However, cumulus cells must provide glucose metabolites such as pyruvate to the oocyte to support its metabolism (as the immature oocyte has limited capability for metabolising glucose [39]), so that a fine balance of sparing oxygen for the oocyte and utilising oxygen to produce pyruvate must be met in these cells. On the other hand the metabolism of the mural granulosa is able to be largely anaerobic which allows as much oxygen as possible through to the developing follicle. It is known that removal of the cumulus cell matrix from the oocyte is detrimental to oocyte development $[40,41]$ and the metabolic support that cumulus cells provide to the oocyte makes inclusion of the whole COC in IVM systems desirable [5]. On the other hand, it seems that mural granulosa cells are important for folliculogenesis rather than providing the oocyte with nutrients [36]. Mathematical models of this type applied to other important nutrients, for example, may provide further insight into the differing roles of these two cell types in oocyte development that may lead to improvements in in vitro handling of oocytes and COCs.

Neither this model, nor previous models of $\mathrm{O}_{2}$ transport in the antral follicle $[14,15,26]$, account explicitly for angiogenesis. Angiogenesis occurs around the follicle in response to the release of stimulating chemicals released from follicular cells $[42,43]$. One of these chemicals, vascular endothelial growth factor (VEGF), is known to have increased expression as a response to hypoxia [43]. In addition, at least in pigs, angiogenesis appears to begin in medium-sized follicles [43]. This coincides with a stage of development when models of nutrient transport in the follicle suggest a significant drop in both dissolved follicular fluid $\mathrm{O}_{2}$ concentrations and $\mathrm{O}_{2}$ availability to the oocyte. This lends support to the suggestion that follicular growth is limited by both the nutrient environment within the follicle [14] as well as the development of an adequate vascular supply [43]. An unevenly distributed vascular supply to the follicle is not expected to have much effect on the uniformity of $\mathrm{O}_{2}$ concentration within the follicular fluid, unless there are large "gaps" in the vascular supply. This is due to the small size of $\mathrm{O}_{2}$ molecules meaning that they diffuse readily across membranes and through extracellular material. However, the distribution of vascularisation may have implications for the transport of larger molecules in the follicle.

The data for cell number versus follicle radius used in this study is for human antral follicles, whilst other model parameters are determined for bovine follicles. The location of the local maximum for $\mathrm{O}_{2}$ concentrations in follicular fluid and at the COC could be predicted more accurately with data on bovine granulosa cell number versus follicle radius should this become available. Similarly, with accurate parameterization, this model can be applied to humans or other mammalian species, as well as for other substrates that diffuse easily across cell membranes.

The model represents an idealised spherical follicle containing a spherical COC and does not account for $\mathrm{O}_{2}$ consuming cells in any "stem" attaching the COC to the follicle wall, nor the structural and functional changes in the COC prior to ovulation. A "stem" of cumulus cells will slightly reduce the $\mathrm{O}_{2}$ concentration reaching the COC. Therefore, this idealised geometry will slightly overestimate the $\mathrm{O}_{2}$ environment seen by the COC. In the final stages of maturation, immediately before ovulation, the cumulus cell mass expands, so the space between cumulus cells increases and the extracellular material surrounding these cells becomes mucinous [40]. Computation of oxygen concentrations at this final stage of maturation may require appropriate changes to the model geometry and, probably, the rate of oxygen diffusion through the cumulus matrix toward the oocyte, that is, the diffusion coefficient in this region. Finally the model assumes that COC oxygen consumption is constant throughout maturation. An increase in oxygen demand by the COC, for example, late in development, would lower follicular oxygen levels significantly (see Table 1) which may restrict oxygen availability to the oocyte.

\section{Summary}

We have described a mathematical model of $\mathrm{O}_{2}$ transport in the antral follicle so as to link the $\mathrm{O}_{2}$ concentration in follicular fluid (measured using fluid aspirated from the ovary) with the $\mathrm{O}_{2}$ environment of the COC itself, taking into account the structure of the follicle. This model differs from previous models of nutrient transport in the ovarian follicle $[14,15,26]$ in its explicit inclusion of the COC. It predicts the $\mathrm{O}_{2}$ concentration seen by the oocyte to differ significantly from the mean concentration in the follicle antrum showing that follicle structure as well as perifollicular $\mathrm{O}_{2}$ supply can affect the ability of an oocyte to successfully mature. Our model enables a better informed use of follicular fluid $\mathrm{O}_{2}$ concentration as an indicator of developmental competence of oocytes. Hence, it enables better informed selection of oocytes for use in assisted reproduction technology programs and better choice of culture conditions for in vitro maturation of oocytes.

\section{Acknowledgments}

A. R. Clark was supported in this work by a University of Adelaide scholarship (Adelaide Scholarships International, ASI). The authors are thankful for helpful comments from Associate Professor J. G. Thompson (Obstetrics and Gynaecology, The University of Adelaide) and an anonymous referee.

\section{References}

[1] R. B. Gilchrist and J. G. Thompson, "Oocyte maturation: emerging concepts and technologies to improve developmental potential in vitro," Theriogenology, vol. 67, no. 1, pp. 6-15, 2007.

[2] J. van Blerkom, M. Antczak, and R. Schrader, "The developmental potential of the human oocyte is related to the dissolved oxygen content of follicular fluid: association with vascular enothelial growth factor levels and perifollicular 
blood flow characteristics," Human Reproduction, vol. 12, no. 5, pp. 1047-1055, 1997.

[3] "Mammalian graafian follicle," http://www.microscopy.fsu. edu/primer/anatomy/brightfieldgallery/mammaliangraafianfollicle40xsmall.html.

[4] C. Y. Andersen, "Characteristics of human follicular fluid associated with successful conception after in vitro fertilization," Journal of Clinical Endocrinology and Metabolism, vol. 77, no. 5, pp. 1227-1234, 1993.

[5] T. J. Child, S. J. Phillips, A. K. Abdul-Jalil, B. Gulekli, and S. L. Tan, "A comparison of in vitro maturation and in vitro fertilization for women with polycystic ovaries," Obstetrics and Gynecology, vol. 100, no. 4, pp. 665-670, 2002.

[6] G. N. Piquette, "The in vitro maturation (IVM) of human oocytes for in vitro fertilization (IVF): is it time yet to switch to IVM-IVF?" Fertility and Sterility, vol. 85, no. 4, pp. 833-835, 2006.

[7] R.-C. Chian, "In-vitro maturation of immature oocytes for infertile women with PCOS," Reproductive BioMedicine Online, vol. 8, no. 5, pp. 547-552, 2004.

[8] W. Y. Son, S. J. Park, C. S. Hyun, W. D. Lee, S. H. Yoon, and J. H. Lim, "Successful birth after transfer of blastocysts derived from oocytes of unstimulated woman with regular menstrual cycle after IVM approach," Journal of Assisted Reproduction and Genetics, vol. 19, no. 11, pp. 541-543, 2002.

[9] A. M. Calado, E. Rocha, A. Colaço, and M. Sousa, "A stereological study of medium antral follicles during the bovine estrous cycle," Tissue and Cell, vol. 35, no. 5, pp. 313323, 2003.

[10] M. L. Leibfried-Rutledge, E. S. Critser, J. J. Parrish, and N. L. First, "In vitro maturation and fertilization of bovine oocytes," Theriogenology, vol. 31, no. 1, pp. 61-74, 1989.

[11] R. Roberts, S. Franks, and K. Hardy, "Culture environment modulates maturation and metabolism of human oocytes," Human Reproduction, vol. 17, no. 11, pp. 2950-2956, 2002.

[12] M. L. Sutton, R. B. Gilchrist, and J. G. Thompson, "Effect of in-vivo and in-vitro environments on the metabolism of the cumulus-oocyte complex and its influence on oocyte developmental capacity," Human Reproduction Update, vol. 9, no. 1, pp. 35-48, 2003.

[13] N. M. Orsi, N. Gopichandran, H. J. Leese, H. M. Picton, and S. E. Harris, "Fluctuations in bovine ovarian follicular fluid composition throughout the oestrous cycle," Reproduction, vol. 129, no. 2, pp. 219-228, 2005.

[14] G. P. Redding, J. E. Bronlund, and A. L. Hart, "Mathematical modelling of oxygen transport limited follicle growth," Reproduction, vol. 133, no. 6, pp. 1095-1106, 2007.

[15] G. P. Redding, J. E. Bronlund, and A. L. Hart, "Theoretical investigation into the dissolved oxygen levels in follicular fluid of the developing human follicle using mathematical modelling," Reproduction, Fertility and Development, vol. 20, no. 3, pp. 408-417, 2008.

[16] J. Van Blerkom, "Epigenetic influences in oocyte developmental competence: perifollicular vascularity and intrafollicular oxygen," Journal of Assisted Reproduction and Genetics, vol. 15, no. 5, pp. 226-234, 1998.

[17] S. Huey, A. Abuhamad, G. Barroso et al., "Perifollicular blood flow Doppler indices, but not follicular $\mathrm{pO}_{2}, \mathrm{pCO}_{2}$, or $\mathrm{pH}$, predict oocyte developmental competence in in vitro fertilization," Fertility and Sterility, vol. 72, no. 4, pp. 707-712, 1999.

[18] P. D. Cetica, L. N. Pintos, G. C. Dalvit, and M. T. Beconi, "Antioxidant enzyme activity and oxidative stress in bovine oocyte in vitro maturation," IUBMB Life, vol. 51, no. 1, pp. 57-64, 2001.

[19] J. J. Eppig and K. Wigglesworth, "Factors affecting the developmental competence of mouse oocytes grown in vitro: oxygen concentration," Molecular Reproduction and Development, vol. 42, no. 4, pp. 447-456, 1995.

[20] R. B. L. Gwatkin and A. A. Haidri, "Oxygen requirements for the maturation of hamster oocytes," Journal of Reproduction and Fertility, vol. 37, no. 1, pp. 127-129, 1974.

[21] A. A. Haidri, I. M. Miller, and R. B. L. Gwatkin, "Culture of mouse oocytes in vitro, using a system without oil or protein," Journal of Reproduction and Fertility, vol. 26, no. 3, pp. 409411, 1971.

[22] S. Hashimoto, N. Minami, R. Takakura, M. Yamada, H. Imai, and N. Kashima, "Low oxygen tension during in vitro maturation is beneficial for supporting the subsequent development of bovine cumulus-oocye complexes," Molecular Reproduction and Development, vol. 57, no. 4, pp. 353-360, 2000.

[23] J. I. Park, J. Y. Hong, H. Y. Yong, W. S. Hwang, J. M. Lim, and E. S. Lee, "High oxygen tension during in-vitro oocyte maturation improves in vitro development of porcine oocytes after fertilization," Animal Reproduction Science, vol. 87, no. 12, pp. 133-141, 2005.

[24] R. R. Yeoman, L. E. Williams, and C. R. Abee, "Low oxygen inhibits but complex high-glucose medium facilitates maturation of squirrel monkey oocyte-granulosa cell complexes," Journal of Assisted Reproduction and Genetics, vol. 16, no. 2, pp. 102-107, 1999.

[25] R. J. Rodgers and H. F. Irving-Rodgers, "Formation of the ovarian follicular antrum and follicular fluid," Biology of Reproduction, vol. 82, no. 6, pp. 1021-1029, 2010.

[26] R. G. Gosden and J. G. Byatt-Smith, "Oxygen concentration gradient across the ovarian follicular epithelium: model, predictions and implications," Human Reproduction, vol. 1, no. 2, pp. 65-68, 1986.

[27] F. D. Houghton, J. G. Thompson, C. J. Kennedy, and H. J. Leese, "Oxygen consumption and energy metabolism of the early mouse embryo," Molecular Reproduction and Development, vol. 44, no. 4, pp. 476-485, 1996.

[28] D. P. Jones, "Effect of mitochondrial clustering on $\mathrm{O}_{2}$ supply in hepatocytes," The American Journal of Physiology, vol. 247, no. 1, pp. C83-C89, 1984.

[29] I. Gordon, Laboratory Production of Cattle Embryos, CABI Publishing, Oxford, UK, 2nd edition, 2003.

[30] H. G. Clarke, S. A. Hope, S. Byers, and R. J. Rodgers, "Formation of ovarian follicular fluid may be due to the osmotic potential of large glycosaminoglycans and proteoglycans," Reproduction, vol. 132, no. 1, pp. 119-131, 2006.

[31] I. L. van Wezel, M. Krupa, and R. J. Rodgers, "Development of the membrana granulosa of bovine antral follicles: structure, location of mitosis and pyknosis, and immunolocalization of involucrin and vimentin," Reproduction, Fertility and Development, vol. 11, no. 1, pp. 37-48, 1999.

[32] A. R. Clark, Y. M. Stokes, M. Lane, and J. G. Thompson, "Mathematical modelling of oxygen concentration in bovine and murine cumulus-oocyte complexes," Reproduction, vol. 131, no. 6, pp. 999-1006, 2006.

[33] T. Arlotto, J. L. Schwartz, N. L. First, and M. L. LeibfriedRutledge, "Aspects of follicle and oocyte stage that affect in virtro maturation and development of bovine oocytes," Theriogenology, vol. 45, no. 5, pp. 943-956, 1996.

[34] G. A. Perry, M. F. Smith, M. C. Lucy et al., "Relationship between follicle size at insemination and pregnancy success," 
Proceedings of the National Academy of Sciences of the United States of America, vol. 102, no. 14, pp. 5268-5273, 2005.

[35] G. A. Perry, M. F. Smith, A. J. Roberts, M. D. MacNeil, and T. W. Geary, "Relationship between size of the ovulatory follicle and pregnancy success in beef heifers," Journal of Animal Science, vol. 85, no. 3, pp. 684-689, 2007.

[36] K. Sugiura and J. J. Eppig, "Control of metabolic cooperativity between oocytes and their companion granulosa cells by mouse oocytes," Reproduction, Fertility and Development, vol. 17, no. 7, pp. 667-674, 2005.

[37] K. Sugiura, F. L. Pendola, and J. J. Eppig, "Oocyte control of metabolic cooperativity between oocytes and their companion granulosa cells," Developmental Biology, vol. 279, no. 1, pp. 2030, 2005.

[38] A. R. Clark, Y. Stokes, and J. Thompson, "Estimation of glucose uptake by ovarian follicular cells," Annals of Biomedical Engineering, vol. 39, no. 10, pp. 2654-2667, 2011.

[39] H. J. Leese and A. M. Barton, "Production of pyruvate by isolated mouse cumulus cells," Journal of Experimental Zoology, vol. 234, no. 2, pp. 231-236, 1985.

[40] J. J. Eppig, M. O’Brien, and K. Wigglesworth, "Mammalian oocyte growth and development in vitro," Molecular Reproduction and Development, vol. 44, no. 2, pp. 260-273, 1996.

[41] S. Tanghe, A. Van Soom, H. Nauwynck, M. Coryn, and A. De Kruif, "Minireview: functions of the cumulus oophorus during oocyte maturation, ovulation and fertilisation," Molecular Reproduction and Development, vol. 61, no. 3, pp. 414-424, 2002.

[42] M. Neeman, R. Abramovitch, Y. S. Schiffenbauer, and C. Tempel, "Regulation of angiogenesis by hypoxic stress: from solid tumours to the ovarian follicle," International Journal of Experimental Pathology, vol. 78, no. 2, pp. 57-70, 1997.

[43] C. Tamanini and M. De Ambrogi, "Angiogenesis in the developing follicle and corpus luteum," Reproduction in Domestic Animals, vol. 39, no. 4, pp. 206-216, 2004.

[44] M. L. Sutton, P. D. Cetica, M. T. Beconi, K. L. Kind, R. B. Gilchrist, and J. G. Thompson, "Influence of oocyte-secreted factors and culture duration on the metabolic activity of bovine cumulus oocyte complexes," Reproduction, vol. 126, no. 1, pp. 27-34, 2003.

[45] M. L. Sutton-McDowall, R. B. Gilchrist, and J. G. Thompson, "Cumulus expansion and glucose utilisation by bovine cumulus-oocyte complexes during in-vitro maturation: the influence of glucosamine and follicle-stimulating hormone," Reproduction, vol. 128, no. 3, pp. 313-319, 2004. 


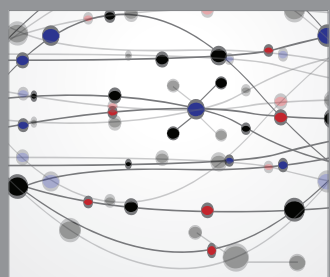

The Scientific World Journal
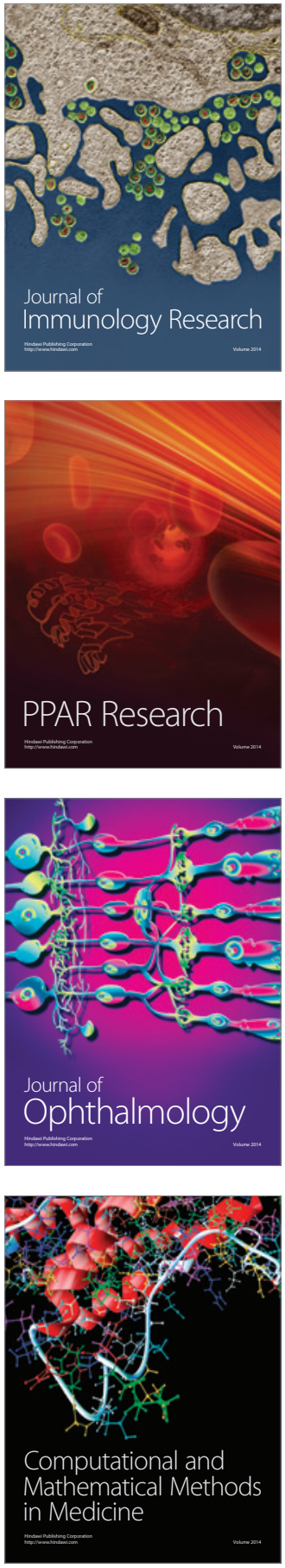

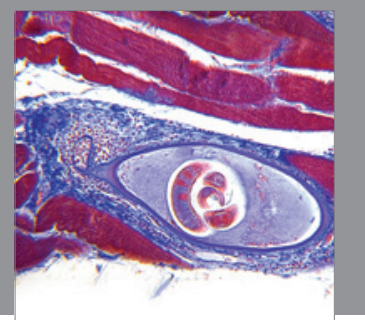

Gastroenterology

Research and Practice
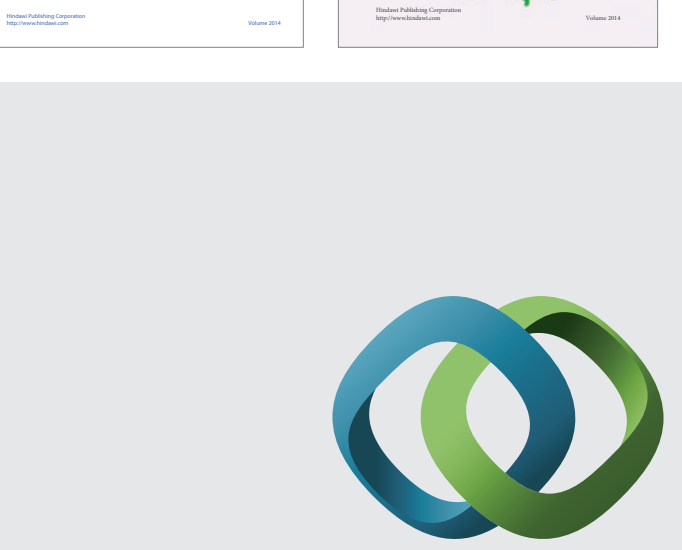

\section{Hindawi}

Submit your manuscripts at

http://www.hindawi.com
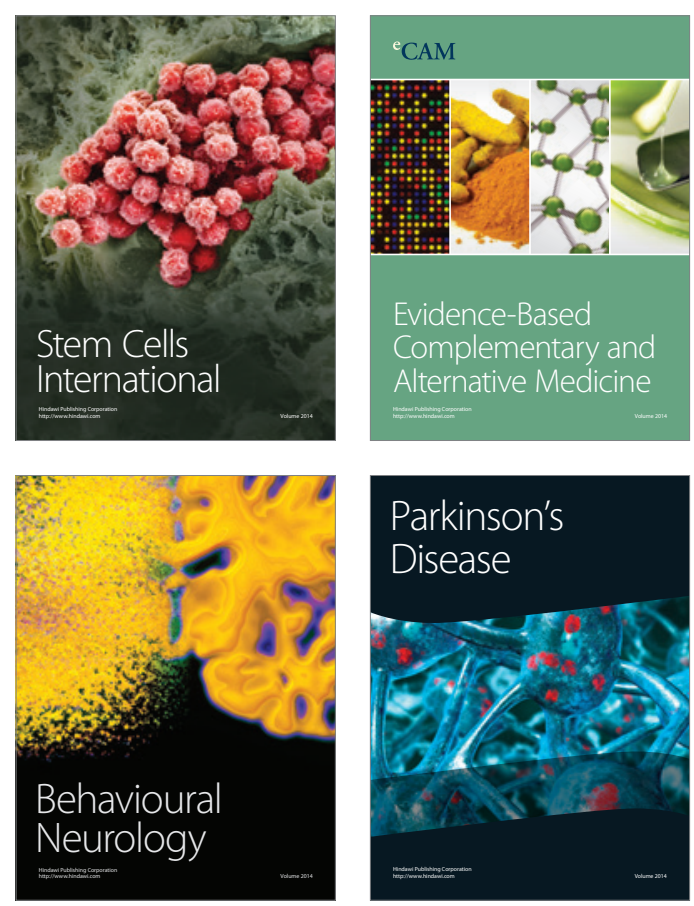

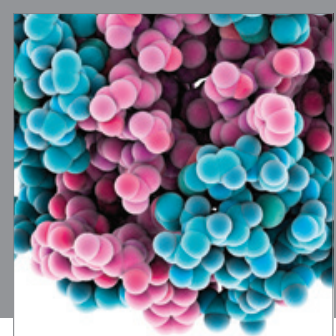

Journal of
Diabetes Research

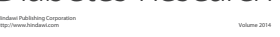

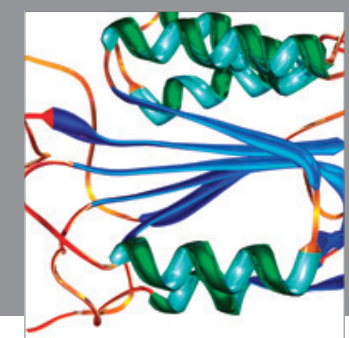

Disease Markers
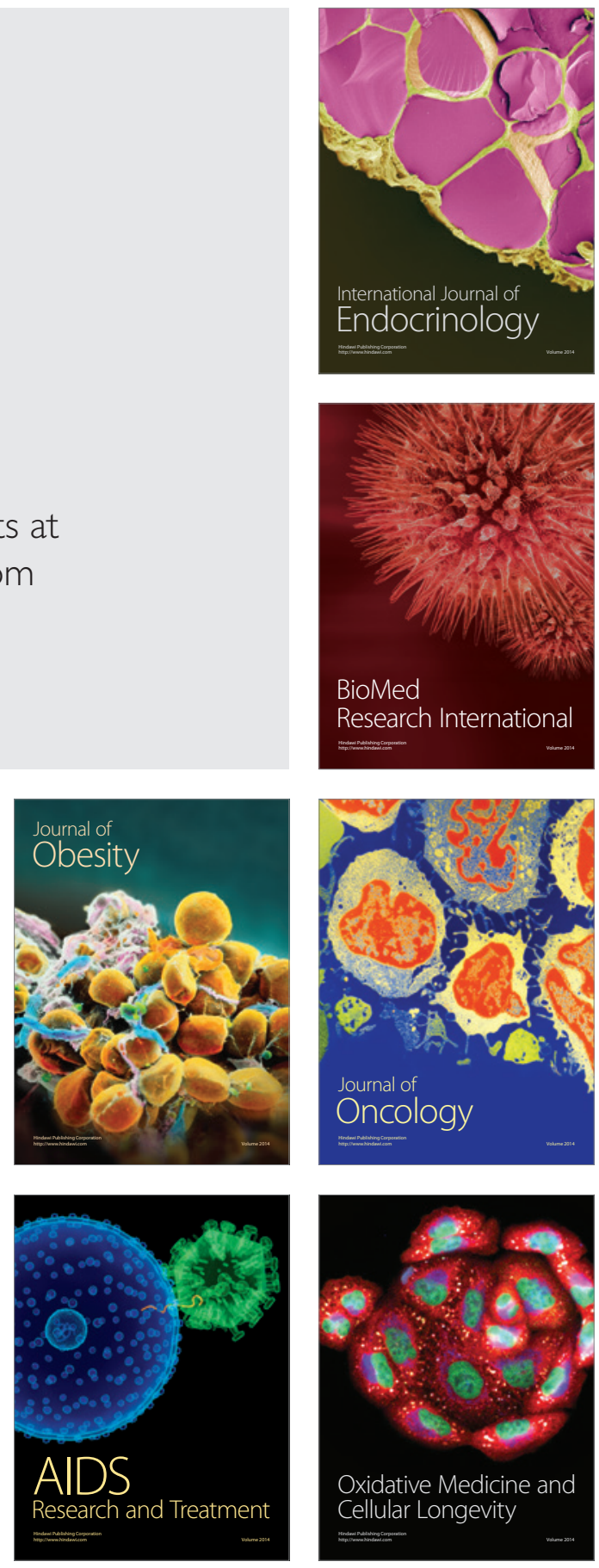